\title{
Strategies on Teacher Professional Development in Big Data Era
}

\author{
Hongtao Cui ${ }^{1, ~ a}$, Dandan Zhang, b \\ ${ }^{1}$ Liaoning Institute of Science and Engineering, Jinzhou, 121013, China \\ ${ }^{2}$ Bohai University, Jinzhou, 121013, China \\ a 570586680@qq.com, b95769270@qq.com
}

Keywords: big data; teacher; professional development; strategies

\begin{abstract}
Big data era to create more learning platform, provides more learning methods, teachers put forward higher requirements, teachers must change their educational concepts, update teaching methods, continuous learning and progress. This paper studies the impact of big data on education and the content of teacher professional development. It analyzes the teachers' professional development is facing the challenge of big data knowledge, the change of teacher's function, the change of student's main body and the way of teaching evaluation. Development Strategy. Specific strategies include: cultivating awareness of big data and enhancing the wisdom of big data; updating professional development approaches and establishing a new online cooperation alliance model; enhancing resource integration capabilities and developing data analysis capabilities; establishing lifelong learning philosophy and continuously updating knowledge structure; Professional development and practical transformation.
\end{abstract}

\section{Introduction}

Professional development of teachers refers to teachers who, through professional organizations, acquire professional knowledge and skills in education through professional life-long training throughout their professional career, implement professional autonomy, show professional ethics, and gradually improve their own teaching quality to become a good educational work The professional growth process, that is, from "ordinary people" to "educator" professional development process. Teachers' professional development is essentially the continuous development of individual teachers and is a process in which teachers constantly receive new knowledge and increase their professional abilities. Teachers to become a mature professional, you need to continue learning and exploration, to expand professional content, improve professional standards, to achieve the professional maturity. The main purpose of teacher professional development is to improve their own quality and lifelong learning ability, keep pace with the times, innovate constantly, improve teaching quality and improve teaching effect.

The impact of big data on education is very obvious. The traditional teaching methods of classroom teaching, unified teaching materials, and teachers' teaching of "teaching" have changed with the wide application of information technology. In the era of big data, more learning platforms have been created, more learning methods have been provided, higher requirements have been placed on educators, education concepts must be changed, teaching methods updated, and learning and progress continued. With the advent of the big data era and its huge impact on education, teachers' professional development faces many difficulties and challenges. How to better define the professional development characteristics of teachers and find effective strategies for professional development under the background of the big data era is an important issue to be solved urgently by teachers, schools and education management departments at this stage.

\section{Big Data Make a Difference in Education}

Big data is not a trend of new technology. It is a process of how to develop and utilize data to lay a foundation for the development of new business model after the high development of information 
technology. It is a problem-solving idea based on new tools. Similarly, big data Have a profound impact on education.

(1) Big data help personalized education. Personalized education is the direction of education for the era of knowledge-based economy. The implementation of personalized education is an important part of promoting innovation in education, an important measure in implementing quality education and a concrete manifestation of implementing the people-oriented scientific concept of development. Using big data technology, real-time recording each student's learning behavior, teachers access to a comprehensive and rich data content, the use of data mining techniques to master individual learning status and knowledge of the acceptance level, to understand the effective teaching methods and student weaknesses. Based on these data, teachers can make individualized teaching plans, teaching activities and study plans for individual students according to their aptitudes, from generalized group teaching to individualize individual teaching.

(2) Change the educational research on the value of the data. Traditional methods of data collection can only highlight the group level of students, including the overall academic level, physical development and physical condition, social emotional and adaptive development, school satisfaction and so on. These data are obtained under the premise of students, with compulsive and deliberate, can not accurately reflect the real situation of students. The advantage of big data is that you can focus on the micro-performance of students, meaningless to other individuals. However, by combining the data of all students, you can answer various questions that you have encountered in the education process, and even some difficult problems that you can not solve in the past. These data are collected without the knowledge of students, data collection and student behavior are independent, and the data is more objective and authentic.

(3) Promote profound changes in educational philosophy. The concept of education is a concept of educational methods, which is formed by educational subjects in teaching practice and educational thinking activities. The rational and subjective requirements of "education should be realized" include educational purposes, educational mission, educational purposes, educational ideals, education Objectives, educational requirements and educational principles and other specific content. Big data has changed the concept of education and changed the understanding of data values in education research. In addition to the exams, big data is infiltrated in all aspects of the classroom, curriculum and teacher-student interaction. Through the analysis of educational data, digging out the teaching, learning and assessment and other links, in line with the actual situation of students and teaching information, to provide the basis for education managers to formulate in line with the actual education and teaching strategies.

(4) Expand new ideas for education evaluation. Educational evaluation is based on a certain educational values or educational goals, the use of effective evaluation techniques and means, through the systematic collection of information and analysis, the education activities to meet the needs of the educational needs of the value judgments made. Big data promotes the developmental evaluation of students, systematically collects the evaluation information and carries on the analysis, carries on the value judgment to the school's education activity, realizes the student's development goal. Big data provides multiple ways to participate in the evaluation, emphasizing the students 'developmental evaluation and overall quality evaluation. The evaluation activities run through the entire learning process of students, covering the students' learning activities and behaviors inside and outside the campus, participating in the participation of multiple parties under different situations Evaluation activities set up a bridge.

\section{Contents on Teacher Professional Development}

The content of teacher professional development is shown in Fig1.

(1) Professional belief. Professional beliefs refer to the concepts or concepts of education that teachers choose, recognize and believe in. They are the beliefs that teachers hold and believe in teaching work, teachers' roles, courses, students and learning and other related factors in teaching situations and teaching processes, affecting the teacher's educational practice and the physical and mental development of students. Professional beliefs to system theory as the basis, with the 
development of the times and update, is an important symbol of teachers gradually toward professional maturity.

\begin{tabular}{|c|c|}
\hline \multicolumn{2}{c|}{ Teacher professional development } \\
\hline Professional belief & Professional ethic \\
\hline Professional knowledge & Professional character \\
\hline Professional ability & Professional wisdom \\
\hline
\end{tabular}

Fig 1 Contents on teacher professional development

(2) Professional knowledge. Professional knowledge includes discipline expertise, education and teaching scientific theoretical knowledge and practical knowledge. Have more profound academic knowledge is the basis for teachers to implement teaching. Theory of education and teaching of scientific theory, including pedagogy, pedagogy, learner knowledge, psychology knowledge and curriculum theory knowledge. Practical knowledge is an important source of teaching ability of teachers, including teaching technical rules, teaching experience, teaching situation and teaching decision-making and other aspects of knowledge.

(3) Professional ability. Competence is the personality trait that one must have to accomplish one activity successfully. Professional ability is the core factor that affects the professional development of teachers, which directly affects and restricts the efficiency of teachers' professional work. Teachers' professional abilities include general ability and special abilities. General abilities include attention, observation, memory and imagination; special abilities include self-control ability, speech combination ability, classroom control ability, knowledge acquisition ability and information technology ability.

(4) Professional ethics Professional ethic. Professional ethics of teachers refers to the professionals engaged in education and teaching, a code of conduct to be followed, and the inner character of cultivating oneself for a better life. It is the moral force embodied in the fulfillment of education and teaching responsibilities and obligations. Based on the experience of being a teacher, we form an inherent and applicable educational code of conduct. Professional ethics teachers in the performance of the teacher, objective and fair, responsible and really good and so on.

(5) Professional character Professional character. Professional character accompanies the teacher's education and teaching activities, which significantly affects teachers' teaching behavior, teaching ability and teaching effect. The core part of the teacher's professional character includes three points: First, lifelong learning. As a teacher, not only to love the profession of teachers, but also determined to teach for life; second, educating people. Teacher's own job not only to teach, but also to educate people; Ask students to do, teachers must first do, in the study of human nature as a role model for others to learn.

(6) Professional wisdom. Education is a science, it is an art. The art most attention to wisdom, the most need wisdom. Education wisdom will not be born out of thin air, can only come from advanced educational theory, stems from a solid educational practice. Teachers' professional wisdom is the result of constant experience, perception, reflection, exploration and creation of teachers in their long-term practice. They are manifested in grasping profound understanding, deep thinking, reasonable judgments and choices, and comprehensive ability to respond flexibly and intelligently.

\section{Challenges on Teacher Professional Development in Big Data Era}

In the era of big data, teachers need to further innovate their teaching philosophy, innovate their teaching modes, constantly improve themselves and follow the pace of the times in line with the innovative thinking of the era of big data. But because big data is new, many teachers do not understand big data and are not aware of the underlying crisis. The professional development of 
teachers in the era of big data is facing many challenges, mainly in the following aspects:

(1) Big data knowledge challenges. The teaching reform under the support of big data is more influential. Internet education and school education are gradually separated. Sharing precision teaching based on data analysis, making effective use of the teaching activities recorded, analyzed and shared by big data, and exploring the latent in the data Education ideas and laws, the pursuit of personnel training flexibility and diversity. Without the knowledge of big data, we can not complete the education in the big data era.

(2) The challenge brought by the change of teacher's function. In the era of big data, the most serious problem of education is that the talented teachers are still working "diligently" in the wrong direction. Big data helps teachers determine the most effective teaching methods. Therefore, in the face of massive information and data, teachers are required to change their functions. Teachers are the guides and leaders of knowledge learning. Teachers are the collaborators and helpers of problem inquiry. Teachers should eventually Efforts toward the direction of life mentor.

(3) Challenges brought about by the change of student body. Big data era, to maximize the potential of students. Students are no longer limited to the way of acquiring knowledge in the classroom and teaching materials, teachers are no longer the only source of knowledge, learning problems can be solved through the network, access to truly customized personalized learning. To adapt to this change, teachers should understand each student's interests, hobbies and concerns from massive data and provide individualized learning solutions according to the students' situation.

(4) The challenge of teaching evaluation method. Teaching evaluation is an effective way to promote teaching. Teaching plan design, teachers' language input, students' autonomous learning and students' internalization of knowledge are the factors to be considered. Education in the era of big data has promoted the developmental assessment of students and provided a multiple-way way to participate in the evaluation. It fully embodies the humane care that promotes the overall quality of students' growth and excludes the positive correlation between the evaluation process and the teaching process.

\section{Strategies on Teacher Professional Development in Big Data Era}

In view of the problems existing in the professional development of teachers, this paper uses the theories of teacher professional development and big data to combine the national policies, laws and regulations with the relevant documents of the education authorities, draws on the experiences of typical developed countries, and according to the characteristics of education big data, The data teacher professional development strategy is as follows:

(1) Cultivate big data awareness, enhance the wisdom of big data. Big data awareness is mainly reflected in three aspects: First, the preservation and integration of existing data, mining new value of the data; the second is to build their own big data system to avoid duplication of work caused by the information gap; the third is to deal with various issues When looking for big data-based solutions. Under the guidance of big data awareness, using big data intelligently will make big data applications more effective. The large amount of data collected is distilled into information and knowledge, and sublimated into wisdom to improve teaching and make full use of the value of big data in the development of education.

(2) To update professional development ways and establish a new mode of online cooperation alliance. As a learning model, online teacher professional development has broken through the traditional way of professional development of teachers and has pushed teachers' professional development to a deeper level with the advantages of fast learning, timely knowledge updating and free learning time. Teachers can rely on online learning platform to play the role of big data to form a coalition of cooperation and development model, the relevant disciplines formed a learning group, the development of learning objectives within the group, a clear personal learning tasks, within the group members of each other's supervision and encouragement, autonomy Learning and self-exploration. This approach has a positive effect on teacher collaboration, academic exchange and wisdom sharing.

(3) Enhance the ability of resource integration and develop data analysis capabilities. The era of 
big data has brought unprecedented opportunities for the construction of educational resources. Much variety of educational resources such as the MOOC class, micro class and flip class have been widely used, and the integration of educational resources has become an important part of teachers' professional development in the era of big data. Big data era also need to master the educational data analysis capabilities, the future data will be presented with an explosive mass of information, teachers should make full use of big data technology, resource-driven construction, the complex data induction, screening and analysis, Find high value and can be used to improve student achievement and promote students' overall development.

(4) Establish the concept of lifelong learning, and constantly update the knowledge structure. Future teachers must be lifelong learning teachers, the future of society must be the dominant knowledge-based society. With the development of science and technology and the constant innovation of knowledge, teachers must establish the concept of lifelong learning and continuously update their personal knowledge structure. The Internet is so popular that it is easy to learn new knowledge, understand new content and create new ways and means of thinking. Teachers must learn lifelong learning, emphasize lifelong learning, and impart the latest knowledge learned to students without reservation. With the latest knowledge structure and knowledge system, can we meet the challenging society.

(5) Turn professional development concept, professional development and practical transformation. The shift of the concept from the subject learning to the focus on the development of information capabilities specifically includes two shifts: the first one is to attach equal importance to both training and independent development, and the awareness and ability to develop teachers on their own should be nurtured. Second, training should be supplemented and self-development oriented. Guide teachers to independent development, to achieve the highest level of professional development of teachers. Practice transformation, from centralized training to school-based training and independent training mode. Specifically, it included two transformations. For the first time, intensive training focused on school-based training and the second was mainly school-based training, which transformed itself from independent training and improved teachers' ability of autonomous learning and self-development.

\section{References}

[1] Z. D. Fei, S. R. Liu, "The Strategy Research of Teacher's Professional Development under the Horizon of 'Big Data'," Journal of Educational Institute of Jilin Province, vol. 33, no. 7, pp. 36-39, 2017.

[2] Aik-Ling Tan, Chew-Hung Chang, Paul Teng. Tensions and Dilemmas in Teacher Professional Developmen [J]. Procedia - Social and Behavioral Sciences, 2015, 174(12): 1583-1591.

[3] X. Y. Zhong, "The new orientation and promoting path of the development of teachers' professional accomplishment in the era of big data," China Adult Education, vol. 25, no. 24, pp. 38-40, 2016.

[4] X. Y. Lin, "The Inspiration of 'Career Management Theory' to Colleges Teacher Professional Development," Teacher Education Forum, vol. 28, no. 7, pp. 66-70, 2015.

[5] Baidu Knows, "What are the aspects of the professional development of Teachers," https://zhidao.baidu.com/question/1111470045532210979.html, 2017-12-5.

[6] R. F. Qu, "Using information platform to promote teachers' professional development," Liaoning Education, vol. 43, no. 14, pp. 49-50, 2014.

[7] Annie Y.N. Cheng, Elson Szeto. Teacher leadership development and principal facilitation: Novice teachers' perspectives [J]. Teaching and Teacher Education, 2016, 58(8): 140-148.

[8] H. Y. Wei, N. Sang, J. F. Xie, et al, "Discussion on the construction mode of integrated team of teaching and scientific research in Colleges and Universities," China Education Innovation Herald, vol. 43, no. 2, pp. 43, 2014. 